\title{
A PREDICTIVE MODEL FOR SCOUR DEPTH OF COASTAL BUILDING FAILURES DUE TO TSUNAMIS
}

\begin{abstract}
Mara Nicholas $^{1}$, Ravindra Jayaratne ${ }^{2}$, Takayuki Suzuki ${ }^{3}$ and Tomoya Shibayama ${ }^{4}$
The 2011 Great East Japan Earthquake and Tsunami was one of the strongest earthquakes which generated a major tsunami in modern history. The tsunami disaster had an estimated cost of 16.9 trillion yen (US\$ 217.3 billion) and affected the Coastal buildings, services, infrastructure and industrial sectors. Approximately $61 \%$ of damaged cost was from the building sector. A practical predictive scour depth model at seaward face was developed to highlight the scour failure of Coastal buildings in Miyagi, Fukushima and Iwate prefectures affected by the 2011 Great East Japan Earthquake and Tsunami. The predictive model for representative scour depth was developed in terms of various hydraulic, geometrical and soil properties affecting Coastal buildings. An analysis was undertaken to investigate the effectiveness of the authors' predictive scour model against the existing models. The results of the authors' proposed model suggested that the tsunami velocity played a significant role on tsunami-induced scour, other scour models such as Tonkin et al.'s model (2003) is reliant on the accuracy of sub models and hydrodynamic forces while the Colorado State University model as modified by Nadal et al. (2010) is reliant on the geometric parameter of the structure.
\end{abstract}

Keywords: 2011 Great East Japan Earthquake and Tsunami, Tsunami-induced, scour, Coastal buildings, Predictive model, Representative scour depth.

\section{INTRODUCTION}

Tsunami-induced scour effects on Coastal buildings is a complex phenomenon which has not been explored by many coastal researchers. The effects of the 2011 Great East Japan Earthquake and Tsunami was widely felt, approximately $535 \mathrm{~km}^{2}$ along the North Eastern Tohoku region inundated by the tsunami. Scouring around the edges of Coastal buildings were one of the structural damage instigators during the 2011 Great East Japan Earthquake and Tsunami and poses a great threat to the structural performance of buildings, under tsunami wave loading conditions (Chock et al., 2013). Kazama and Noda (2012) carried out studies to identify the damages caused by the tsunami event and concluded that the most costly sector affected by the 2011 Tohoku tsunami was the building sector. The ASCE 7 Tsunami loads and design standard guidelines also suggests that tsunami inducedscour effect determines the design of foundations (Chock, 2015). The general parameters required for the design of foundations against tsunami effects include the scour depth and extent (Chock, 2015). The authors reviewed published literature and post-disaster field surveys in order to determine the effective parameters essential to predict the representative scour depth at the seaward corners of damaged Coastal buildings in Tohoku region. In addition to that, comparisons of other generalised predictive scour depth models to the proposed model were also undertaken, in order to identify the robustness and performance of the authors' model. It is believed that this practical model will aid in the design of building foundations by predicting the scour depths accurately under tsunami waves. This paper discusses this phenomena and sheds light on the importance of tsunami-induced scour on building damage and also highlights possible mitigation strategies that can be undertaken for future tsunami events.

\section{FIELD SURVEY OF DAMAGED COASTAL BUILDINGS}

The impact of tsunami-induced scour was evident throught the survey of damaged Coastal buildings. It was observed from the field survey photographs that scour effects at the corners of building foundations contributed to both moderate to heavy damage of buildings. According to Fraser et al. (2013) this occurs when the buildings' foundations were exposed to tsunami wave loading conditions; hence it is imperative to analyze and collect data to predict the extent of scour on buildings during a tsunami event to help mitigate the risk of a Coastal building structurally failing due to the collapse of its foundation. The scour data used to develop the authors' predictive model was collected from various cities in the Tohoku region. This included the three main affected prefectures; Iwate, Miyagi and Fukushima. The main scour related parameters such as scour depths and extent, geographical information, geometric parameters of the affected Coastal buildings, and tsunami inundation heights at various locations along the coastlines were collected from the above prefectures.

\footnotetext{
${ }^{1}$ Miss., Graduate Engineer, J Murphy and Sons Ltd., Hiview House, Highgate Road, London NW51TN maranicholas@murphygroup.co.uk / mj.nicholas01@gmail.com

${ }^{2} \mathrm{Dr}$, Senior Lecturer in Civil Engineering, School of Architecture, Computing \& Engineering, University of East London, Docklands Campus, 4-6 University Way, London E16 2RD, UK. r.jayaratne@uel.ac.uk

${ }^{3} \mathrm{Dr}$, Associate Professor, Department of Civil Engineering, Yokohama National University, Tokiwadai 79-5, Hodogaya-ku, Kanagawa 240-8501, Japan. suzuki-t@ynu.ac.jp

${ }^{4} \mathrm{Dr}$, Professor of Civil \& Environmental Engineering, Faculty of Science \& Engineering, Waseda University, 3-4-1 Okubo, Shinjuku-ku, Tokyo 169-8555, Japan. shibayama@waseda.jp
} 
The detailed post-tsunami field surveys were carried out by the Ministry of Land, Infrastructure, Transport and Tourism of Japan (2011), the Earthquake Engineering Field Investigation Team (2011) and the ASCE Team on Structural Performance (Chock et al., 2013). As seen in Figure 1, a majority of the data (79\%) was collected from Miyagi Prefecture. This is because the Miyagi prefecture recorded some of the highest tsunami inundation heights as high as $16 \mathrm{~m}$ in the Tohoku region and this resulted in greater levels of damage to Coastal buildings.

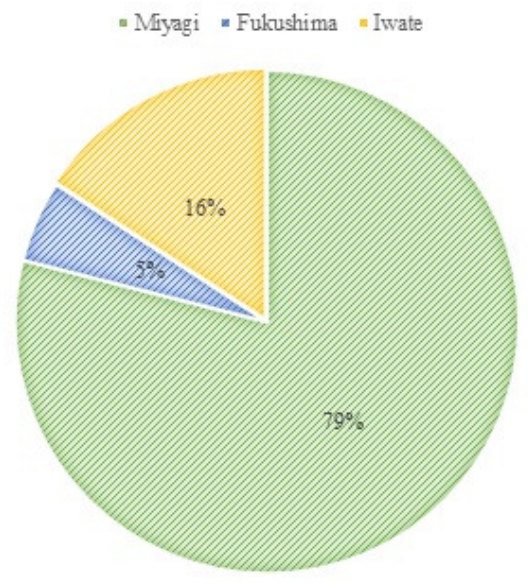

Figure 1. Distribution of collected scour data in three different prefectures in North East Japan.

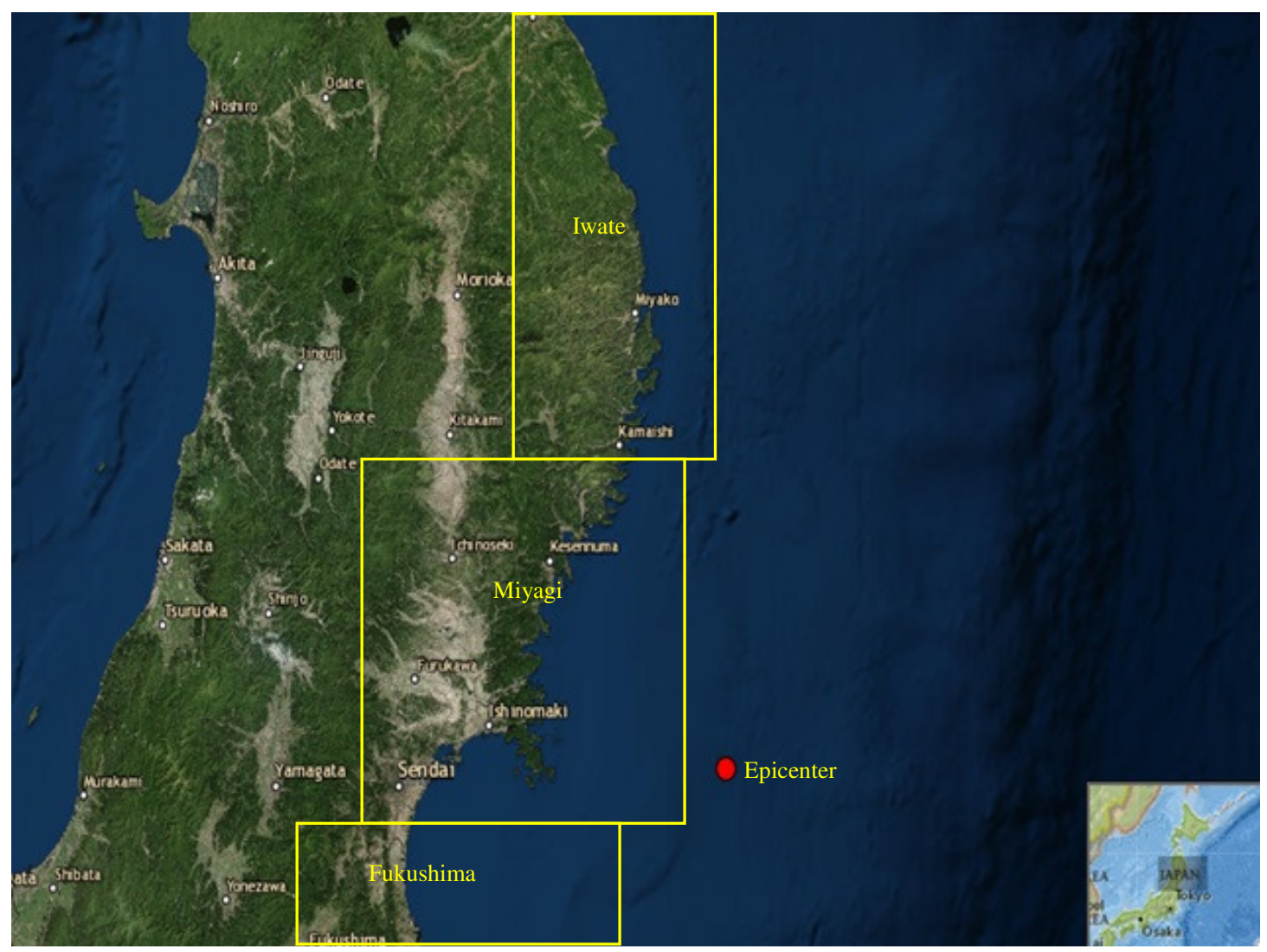

Figure 2. Map highlighting the northern eastern region of Japan (Source: National Centers for Environmental Information: www. ngdc.noaa.gov). 


\section{FLOW PATTERNS OF WATER AROUND COASTAL BUILDINGS}

Wilms et al. (2012) investigated the influence of water flow and sediment transport around a structural foundation. The results from the investigation indicated that a foundation structure was considered as a flow obstacle and therefore influenced scour around the foundation. Wilms et al. (2012) also highlighted that most scour was concentrated around the edge of the foundation structure. A structure within the Coastal environment causes flow patterns in the nearby vicinity to change, this change in flow patterns around the foundation increases bed shear stress and the turbulence level. The increase in those parameters near the structure leads to an increase in the sediment transport in the vicinity of the structure (Sumer and Fredose, 2002). The geometry and flow pattern around a building also influence the sediment transport rates around a structure. This in turn influences location and development of local scour around a structure or a building.

Figs.3, 4, 5 and 6show the damage to buildings due to tsunami-induced scour. As observed in the figures the scour around buildings are concentrated on their edges and also localised to the surroundings of the buildings. Data used in developing the authors' predictive scour model were also taken from the buildings and locations in Figs. 3, 4, 5 and 6.

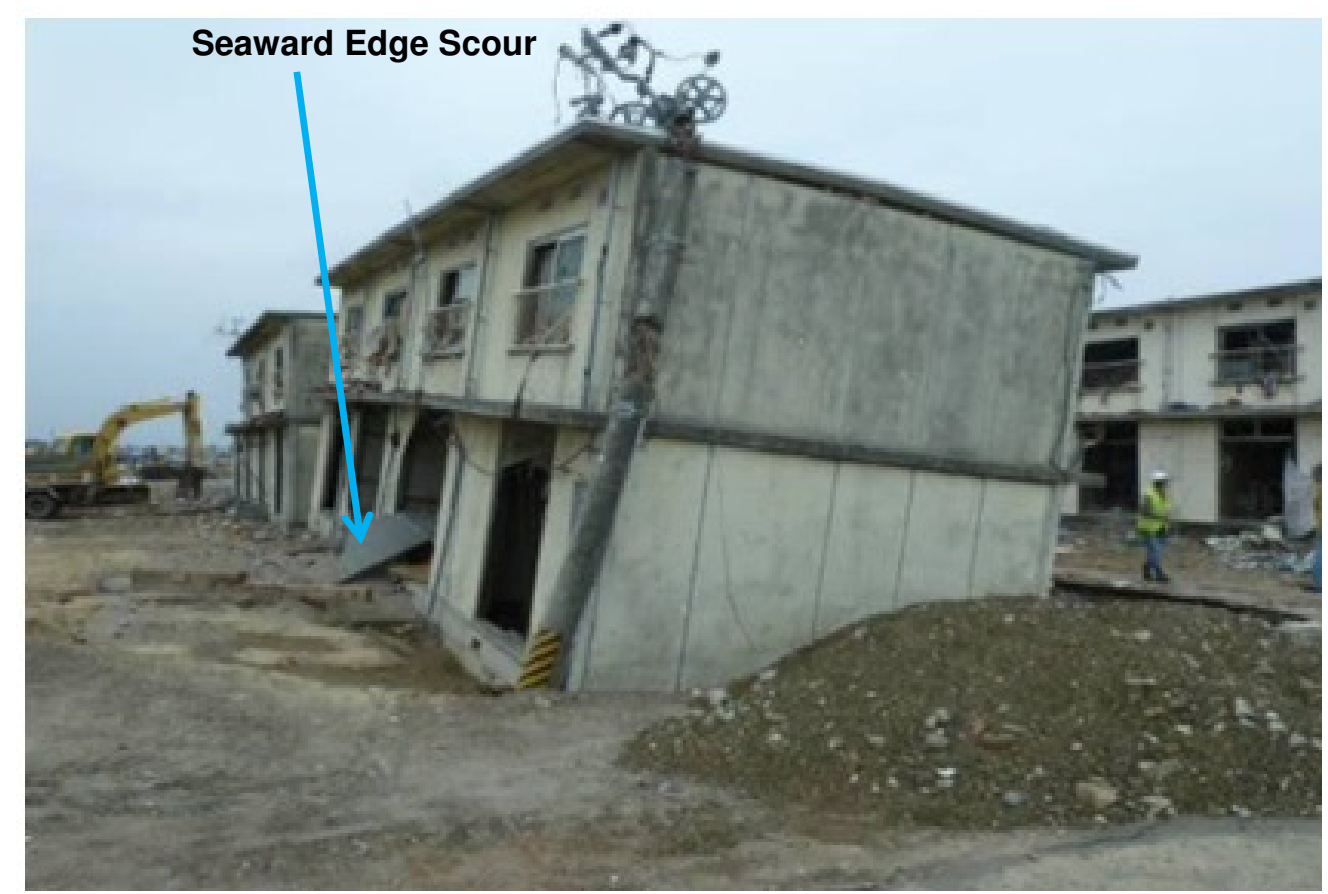

Figure 3. Damaged apartment complex at Yuriage, Natori City, Miyagi prefecture. 


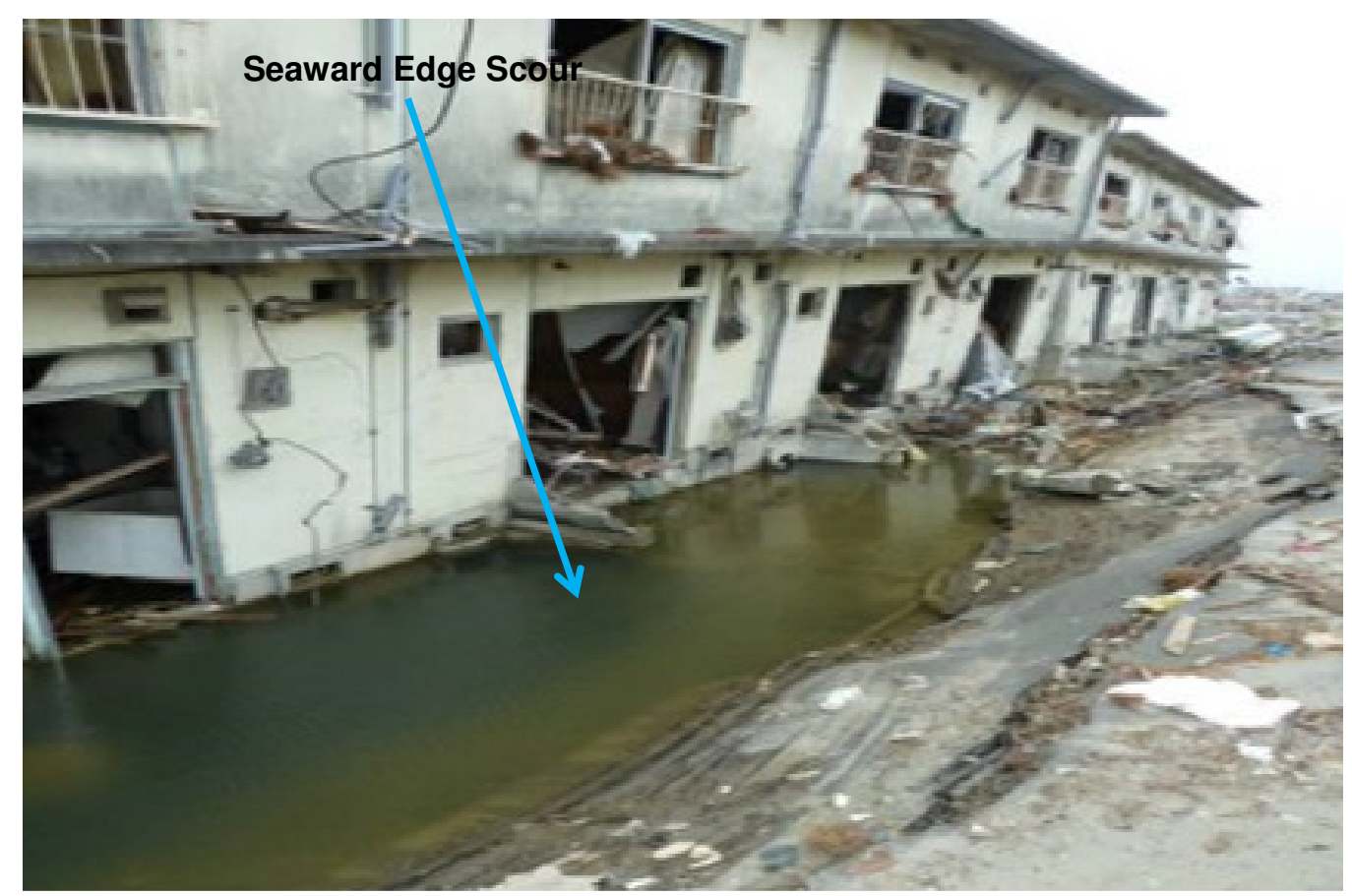

Figure 4. Damaged apartment complex at Yuriage, Natori City, Miyagi prefecture.

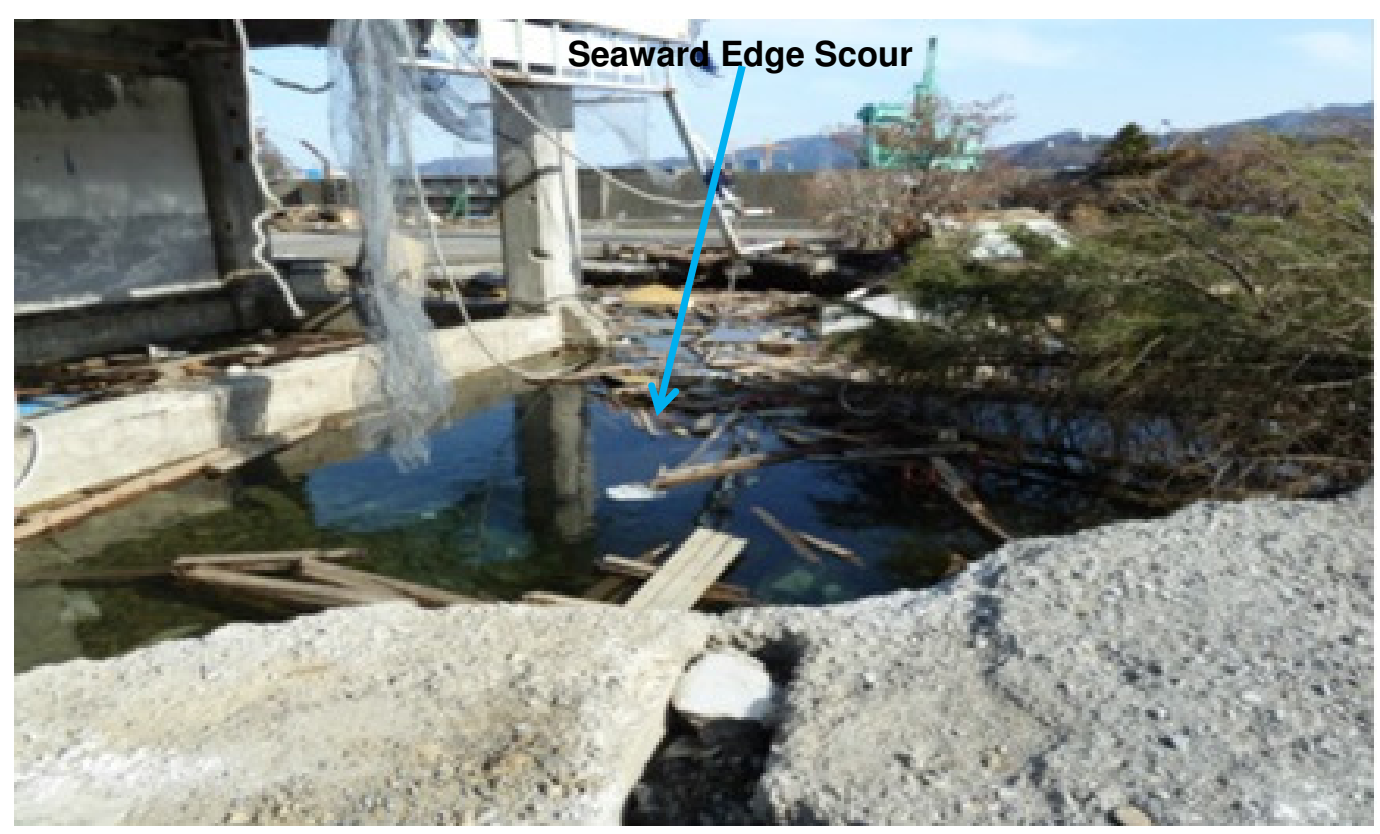

Figure 5. Damaged building at Kamaishi, Iwate prefecture. 


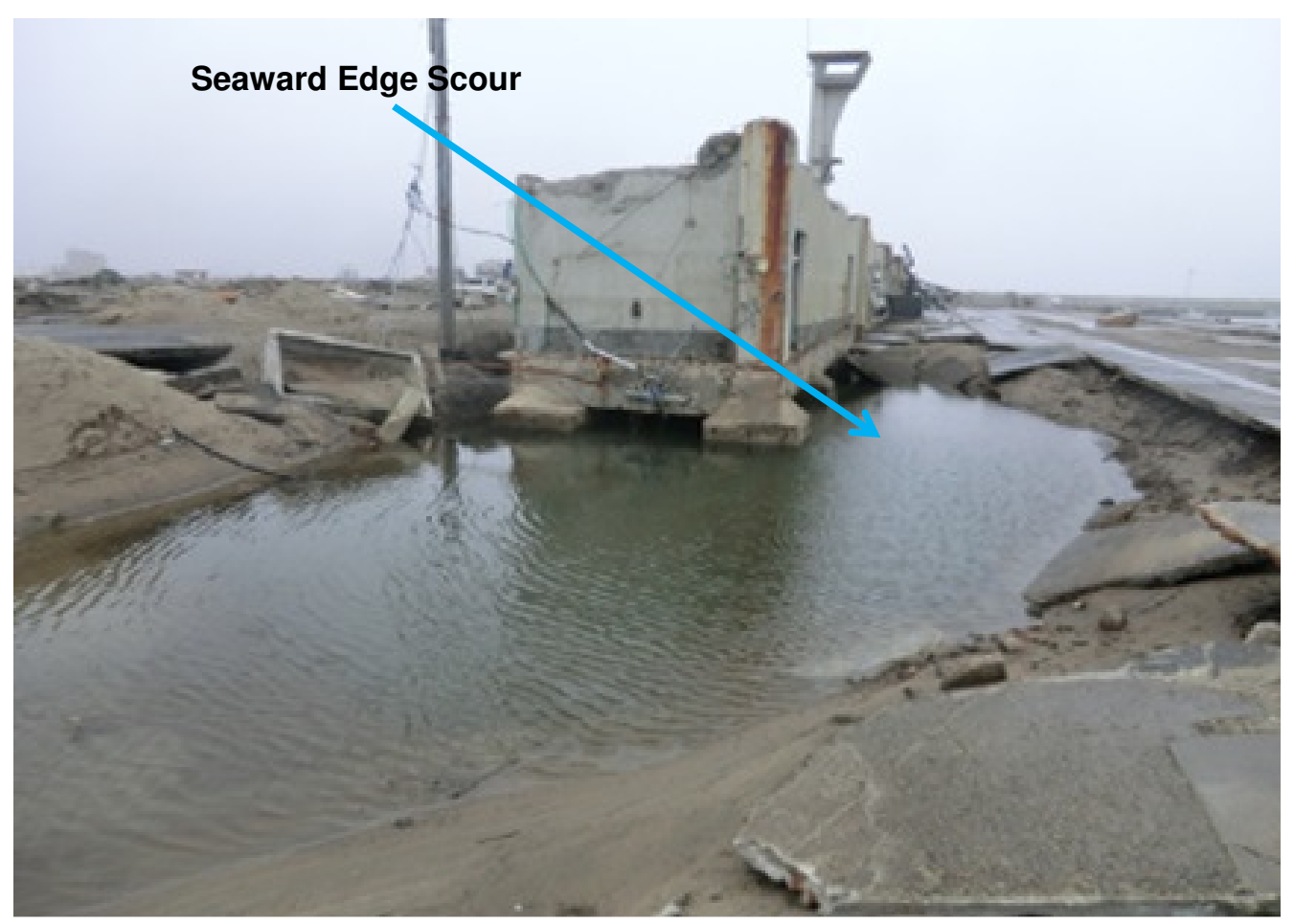

Figure 6. Building at Yuriage Fishing Port, Natori City, Miyagi.

\section{PARAMETERS OF A TSUNAMI CONTRIBUTING TO TSUNAMI-INDUCED SCOUR}

Nadal et al. (2010) suggested that the most influential parameter of tsunami waves on flood damage is its velocity. Nadal et al. (2010) suggested that the velocity of a tsunami can increase flood damage by up to 190 $\%$ in comparison to damage caused by the still flood water. Analysis of damaged buildings due to scour, indicated that the probability of failure rises as the floodwater depth, velocity and flow duration increase (Nadal et al., 2010). The Port and Airport Research Institute, PARI, (2011) also attributed wave parameters such as the tsunami wave height and consequently the velocity, to the increase or decrease of the tsunami wave force. The PARI also stated that strong currents due to high wave forces were the criteria of a tsunami wave that was liable for scour of structures. Therefore, the drag force and strong currents were attributed to the scour process of structures under tsunami wave conditions.

\section{PREDICTIVE MODEL FOR REPRESENTATIVE SCOUR DEPTH}

A scour depth predictive model was developed using the Buckingham $\pi$ theorem, which was used to derive the relationship between relative scour depth, shear velocity, model coefficients based on frictional properties of the soil-surface and geometrical properties of the building such as the seaward width of the building. The dimensional analysis was used to establish non-dimensional terms combining tsunami physics, soil properties and geometrical parameters of the buildings. The mathematical form of non-dimensional terms can be written as in Eq. (1). Finally, a power relationship (Eq. (2)) is deduced for the prediction of scour depth (z) in terms of measurable quantities in the field. 


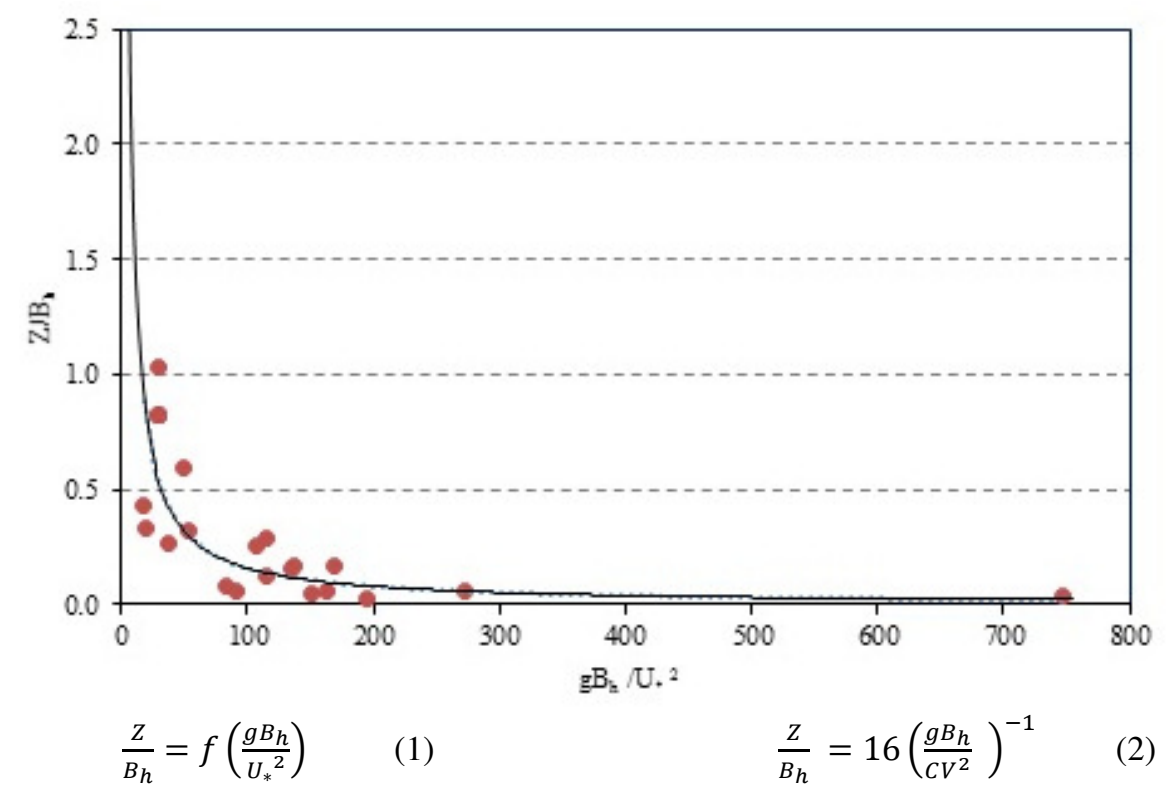

Figure 7. Relationship between representatives scour depth and shear velocity for surveyed locations in NE Japan.

where $z=$ scour depth at the seaward corner of the building, $B_{h}=$ half seaward width of building, $\mathrm{C}=$ DarcyWeisbach friction factor, $\mathrm{V}=$ flow velocity, $U_{*}=$ shear velocity and $g=$ gravitational acceleration.

\section{FOUNDATION DESIGN USING PROPOSED SCOUR DEPTH MODEL}

The model incorporates soil, geometric properties and tsunami wave parameters such as flow velocity to help formulate a scour depth prediction. The practical model can also be used as an aid for the design of building foundations near the coast. The prediction of the scour depth can help determine accurate depths to construct pile foundation system or any other foundation system which is identified as suitable for the building. Hence, recommendations can be given for design of buildings in tsunami prone areas. It can be deduced from the model that longer seaward building widths will contribute to decrease relative scour depth and higher tsunami velocities will result in high relative scour depth. The manning's roughness coefficient of the ground surface also affects the scour depth as it is associated with the Darcy-Weisbach friction factor. Hence changes could be recommended to the design of buildings in tsunami prone areas as follows;

- The buildings should have a smaller width built towards the seaward facing side.

- The surface roughness around the corners of the building should be increased.

- Piling foundations could be adapted in the construction of buildings prone to tsunami scour.

\section{APPLICABILITY OF THE PROPOSED MODEL}

Comparisons were made to validate the efficiency of the proposed predictive model and also to investigate the main parameters affecting the predictive results. One of the main parameters affecting the authors' predictive scour depth around the buildings was its shear velocity. The predictive scour depth value quadrupled when the shear velocity value was doubled. Therefore, this indicated that the shear velocity played a significant role on tsunami induced scour. The shear velocity in a tsunami is also related to other parameters such as tsunami flow velocity and tsunami inundation

Two other suitable models were compared to the authors' proposed model. They included the Colorado State University (CSU) model as suggested by Nadal et al. (2010) and Tonkin et al.'s model (2003) as suggested by Yeh et al. (2013). A sensitive analysis was carried out on all the models, based on the results it was observed that Tonkin et al.'s model (2003) was influenced by the liquefaction enhancement factor $(\Lambda)$. A percentage increase of $100 \%$ on the predicted scour depth was observed when the enhance factor $(\Lambda)$ was doubled. While the CSU model was influenced by the width of the structure. The analysis shows that when the width was doubled the predicted scour depth increased by $57 \%$. 
Tonkin et al.'s model (2003) as suggested by Yeh et al. (2013) is given below:

$$
\mathrm{d}_{\mathrm{s}}=\frac{\Delta \mathrm{p}}{\gamma_{\mathrm{b}} \Lambda}\left(1-4 \mathrm{i}^{2} \operatorname{erfc}\left[\frac{\mathrm{d}_{\mathrm{s}}}{2 \sqrt{\mathrm{c}_{\mathrm{v}} \Delta \mathrm{T}}}\right]\right)
$$

where $d_{s}=$ scour depth, $\gamma_{b}=$ unit weight of soil, $\Lambda=$ liquefaction enhancement factor, $\Lambda(\mathrm{ds})=$ function of the scour depth, $\mathrm{i}^{2} \mathrm{erfc}=$ second integral of the complementary error function, $\Delta \mathrm{P}=$ pressure head, $\Delta \mathrm{T}=$ time difference and $c_{v}=$ a numerical coefficient.

The Colorado State University (CSU) model as suggested by Nadal et al. (2010) is as follows:

$$
\frac{\mathrm{z}_{\mathrm{t}}}{\mathrm{h}}=2.2\left(\frac{\mathrm{b}_{\mathrm{f}}}{\mathrm{h}}\right)^{0.65}(\mathrm{Fr})^{0.43}
$$

where $\mathrm{z}_{\mathrm{t}}=$ scour depth at building foundation, $\mathrm{b}_{\mathrm{f}}=$ one-half width of building in the direction of the flow, $\mathrm{Fr}=$ Froude number, $\mathrm{h}=$ inundation height.

The two existing models consist of various parameters to that of the authors proposed model. For instance, Tonkin et al.'s model (2003) is reliant on the use of other predictive models to predict its scour depth, which suggests that the accuracy of the external model (sub model) will play a significant role in its scour depth output. The CSU model is however heavily reliant on the geometric parameters of the structure to predict its scour depth value.

Finally, the authors' proposed predictive model output is reliant on the shear velocity. Therefore, the analysis indicated that the authors' proposed model outputs were relatively more accurate than that of other two models. Figure 8 depicts the comparison results of all three models against the measured field data.

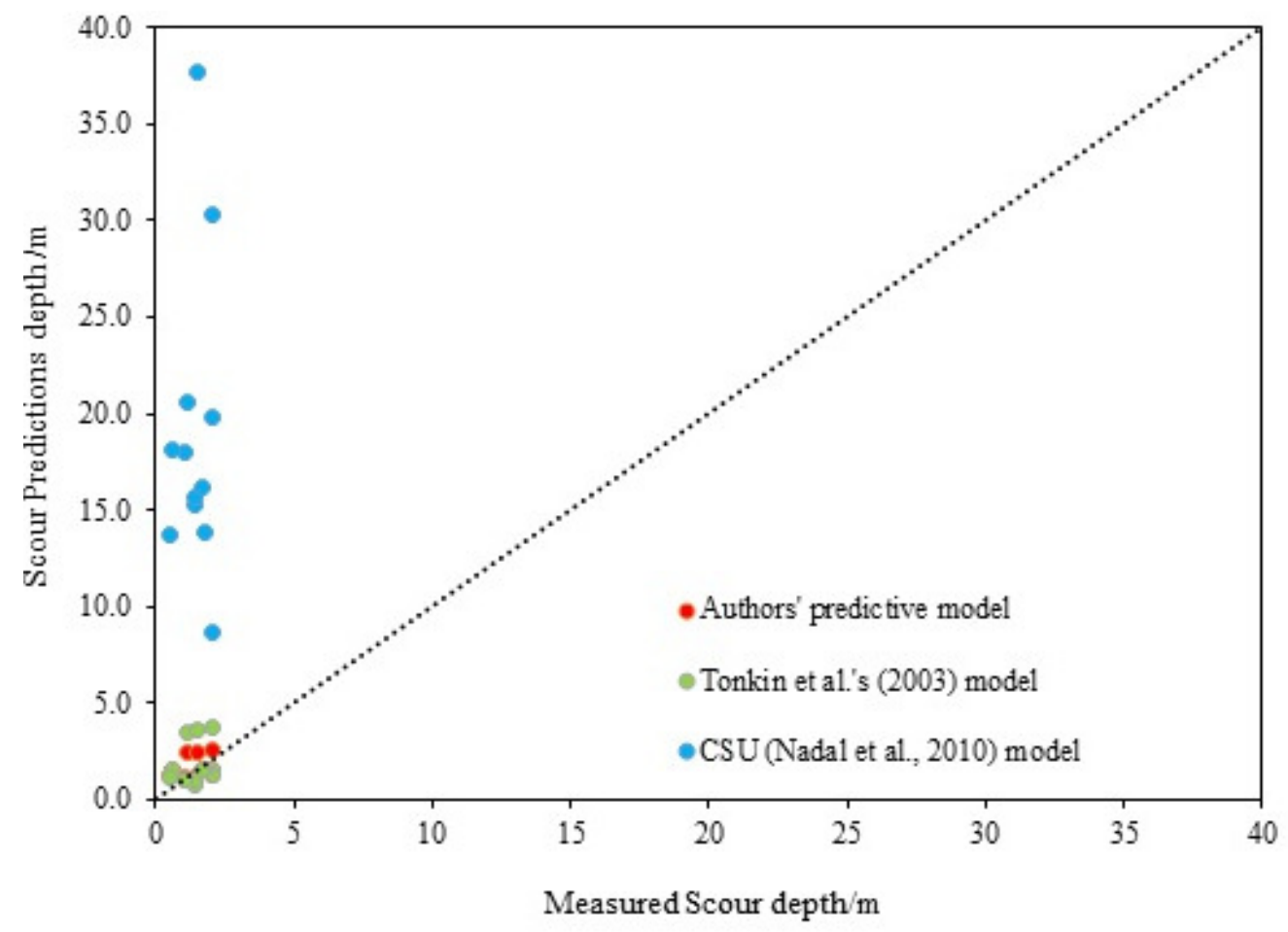

Figure 8. Comparison results of all three predictive models against the measured field data. 


\section{CONCLUDING REMARKS}

A practical predictive model for representative scour depth at Coastal buildings under tsunami wave attack was developed using governing physics and Buckingham $\pi$ theorem. The model was used as a practical tool to predict scour depths using measurable parameters in the field. The existing predictive models were influenced by various factors such as the width of a building for the CSU model (Nadal et al., 2010), the liquefaction enhancement factor for Tonkin et al.'s model (2003) and the shear velocity for the authors' proposed model. The analysis shows that the general disparity of the scour depth prediction of the authors' model is lower than the results given by the other two models however the Tonkin et al.'s model (2003) results are relatively close to the authors'. The authors' predictive model is considered to be the most accurate amongst the three models in predicting scour depth around Coastal buildings at an event of a tsunami. Furthermore, the model can be recommended for the use of foundation design as it incorporates variables such the geometric parameters of the building.

\section{ACKNOWLEDGEMENTS}

The authors would like to acknowledge the financial contribution of the Strategic Research Foundation Grant-aided Project for Private Universities from Ministry of Education (Waseda University, No. S1311028). Also the authors wish to thank the Great Britain Sasakawa Foundation (GBSF) and the University of East London (UEL) for granting funds to carry out field surveys and modelling in the period of 2011-2014.

\section{REFERENCES}

Chock, G. (2015) 'The ASCE 7 Tsunami loads and effects design standard, Structures Congress 2015', Structures Congress 2015, Portland, 23-25 April. United States: American Society of Civil Engineers, pp. 1446-1456.

Chock, G., Robertson, I., Kriebel, D., Francis, M., and Nistor, I. (2013) Tohoku Japan Tsunami of March 11, 2011 Performance of Structures. Virginia: ASCE Publications.

Fraser, S., Raby, A., Pomonis, A., Goda, K.., Chian. S.C., Macabuag, J., Offord, M., Saito, K., and Sammonds, P. (2013) 'Tsunami damage to coastal defences and buildings in the March $11^{\text {th }} 2011 \mathrm{Mw} 9.0$ Great East Japan earthquake and tsunami', Bulletin of Earthquake Engineering, 11(1), pp. 205-239.

Kazama, M. and Noda, T. (2012) 'Damage statistics (Summary of the 2011 off the Pacific Coast of Tohoku Earthquake damage)', Soils and Foundations, 52(5), pp. 780-792.

Nadal, N.C., Zapata, R.E., Pagan, I., Lopez, R. and Agudelo, J. (2010) 'Building Damage due to Riverine and Coastal Floods', Journal of Water Resources Planning and Management, 136(3), pp. 327-336.

Port and Airport Research Institute (PARI) (2011) 'Urgent Survey for 2011 Great East Japan Earthquake and Tsunami Disaster in Ports and Coasts - Part I (Tsunami)' An English Abstract of the Technical Note of Port and Air Port Research Institute, 1231, pp. 200-209.

Sumer, B.M., Fredsøe, J., Lamberti, A., Zanuttigh, B., Dixen, M., Gislason, K. and Di Penta, A.F. (2005) 'Local scour at roundhead and along the trunk of low crested structures', Coastal Engineering, 52, pp. 995-1025.

Wilms, M., Stahlmann, A., \& Schlurmann, T. (2012) 'Investigations on Scour Development Around a Gravity Foundation for Offshore Wind Turbines', International Conference on Coastal Engineering, Santander, 1 July - 6 July [Online] DOI: https://doi.org/10.9753/icce.v33.structures.35.

Yeh, H., Sato, S. and Tajima, Y. (2013) 'The 11 March 2011 East Japan Earthquake and Tsunami: Tsunami Effects on Coastal Infrastructure and Buildings', Pure and Applied Geophysics, 170 (6-8), pp. 1019-1031. 